\title{
Survey of senior resident training in urologic laparoscopy, robotics and endourology surgery in Canada
}

\author{
Mark A. Preston MD; ; Brian D.M. Blew, MD, FRCSC; Rodney H. Breau, MD; ${ }^{*}$ Darren Beiko, MD; \\ Stuart J. Oake, MD, FRCSC; ${ }^{*}$ J.D. Watterson, MD, FRCSC*
}

See related article on page 47

\section{Abstract}

Introduction: We determined the status of Canadian training during senior residency in laparoscopic, robotic and endourologic surgery.

Methods: Fifty-six residents in their final year of urology residency training were surveyed in person in 2007 or 2008.

Results: All residents completed the survey. Most residents $(85.7 \%)$ train at centres performing more than 50 laparoscopic procedures yearly and almost all (96.4\%) believe laparoscopic radical nephrectomy is the gold standard. About $82 \%$ of residents participated in a laparoscopic partial nephrectomy in 2008, compared to $64.7 \%$ in 2007 . Of the respondents, $66 \%$ have participated in a laparoscopic prostatectomy and $54 \%$ believe the procedure has promising potential. Exposure and training in robotic-assisted laparoscopic procedures seem to be increasing as $35.7 \%$ of 2008 residents have access to a surgical robot and $7 \%$ consider themselves trained in robotic-assisted procedures. Most residents $(71.4 \%)$ train at centres that perform percutaneous ablation. However, $65 \%$ state the procedure is performed solely by radiologists. Percutaneous nephrolithotomy is widely performed (98.2\%), but only $37.5 \%$ of residents report training in obtaining primary percutaneous renal access. Despite only $12.5 \%$ of residents ranking their laparoscopic experience as below average or poor, an increasing proportion of graduating residents are pursuing fellowships in minimallyinvasive urology.

Conclusion: Laparoscopic nephrectomy is commonly performed and is considered the standard of care by Canadian urology residents. Robotic-assisted surgery is becoming more common but will require continued evaluation by educators who will ultimately define its role in the urological residency training curriculum. Minimally-invasive surgical fellowships remain popular, as Canadian residents do not feel adequately trained in certain advanced procedures. Urologists must strive to learn and adapt to new technologies or risk losing them to other specialties.

Can Urol Assoc J 2010;4(1):42-6

\section{Résumé}

Introduction : Nous avons vérifié l'état de la formation professionnelle au Canada pendant la dernière année de résidence en chirurgie laparoscopique, endo-urologique et assistée par robotique.
Méthodologie : Un sondage effectué en personne a été mené auprès de 56 résidents dans leur dernière année de résidence en urologie en 2007 et en 2008.

Résultats : Tous les résidents ont répondu au sondage. La plupart $(85,7 \%)$ recevaient leur formation à des centres effectuant plus de 50 interventions par laparoscopie par année et presque tous les répondants $(96,4 \%$ ) croyaient que la néphrectomie radicale par laparoscopie représentait la norme thérapeutique. Environ $82 \%$ des résidents avaient participé à une néphrectomie partielle par laparoscopie en 2008, contre $64,7 \%$ en 2007 . Sur le total des répondants, $66 \%$ avaient participé à une prostatectomie par laparoscopie et $54 \%$ croyaient que cette technique était prometteuse. La formation et l'expérience avec les interventions laparoscopiques assistées par robotique semblent avoir augmenté; en effet, 35,7 \% des résidents en 2008 avaient accès à un robot chirurgical et $7 \%$ considéraient avoir reçu une formation adéquate sur ce type d'intervention. La plupart des résidents $(71,4 \%)$ recevaient leur formation à des centres effectuant des ablations percutanées, mais $65 \%$ affirmaient que ces interventions étaient réalisées uniquement par des radiologues. La néphrolithotomie percutanée est souvent effectuée (98,2 \%), mais seulement $37,5 \%$ des résidents mentionnaient avoir reçu la formation nécessaire sur l'obtention d'une voie d'accès percutanée primaire jusqu'au rein. Malgré que seulement $12,5 \%$ des résidents évaluaient leur expérience en techniques laparoscopiques comme étant en-dessous de la moyenne ou insatisfaisante, une proportion croissante de résidents obtiennent des bourses de recherche dans le domaine des techniques d'urologie minimalement invasives.

Conclusion : La néphrectomie par laparoscopie est une technique souvent utilisée et considérée comme la norme thérapeutique par les résidents canadiens en urologie. La chirurgie assistée par robotique est de plus en plus utilisée mais nécessite des évaluations continues par les enseignants qui définiront en bout de ligne son rôle dans le plan de formation des résidents en urologie. Les bourses de recherche sur les techniques chirurgicales minimalement invasives demeurent populaires, car les résidents canadiens ne se sentent pas suffisamment bien formés pour utiliser certaines techniques chirurgicales plus avancées. Les urologues doivent chercher à mieux connaître les nouvelles technologies et à s'y adapter, sinon ils courent le risque que d'autres spécialités se les approprient. 


\section{Introduction}

Urologic surgery is constantly evolving due to rapid technological advances and novel approaches to urologic conditions. Laparoscopic and percutaneous techniques have become the gold standard for certain urologic diseases and robot-assisted surgery is being widely developed. As urologists strive to maintain quality of care while learning minimal access procedures, there may be an impact on the urology resident training. Therefore it is important to monitor the attitudes and experience of Canadian residents. We present the exposure and opinions of senior urology residents graduating from Canadian training programs in 2007 and 2008.

\section{Methods}

Residents in their final year of training were surveyed in person at the annual Queen's Urology Examination Skills Training (QUEST) course in Kingston, Ontario in February 2007 and 2008. The survey for our study, which had 55 questions, was modified from the version used to evaluate American urology residents in $2006 .{ }^{1}$

\section{Results}

All residents approached $(n=56)$ completed the survey and all provinces with urology training programs $(n=6)$ were represented (Table 1). Responses to selected questions, stratified by year, are presented in Table 2 .

\section{Laparoscopic training}

Most respondents (85.7\%) trained at centres that perform at least 50 laparoscopic procedures each year and most trained at centres with at least 1 surgeon fellowship-trained in laparoscopy (82.1\%). About $67.8 \%$ of Canadian residents reported their laparoscopic experience to be either good or extensive and only $12.5 \%$ believed it to be below average or poor. Of the $75.9 \%$ of residents pursuing a fellowship, $43.9 \%$ will be furthering their training in laparoscopy. The majority of respondents $(85.7 \%)$ had access to dry lab educational materials, including pelvic trainers (75\%), videos and/or CD-ROMs (33.9\%) and virtual reality simulators $(28.6 \%)$. Porcine animal laboratories were used in $69.6 \%$ of centres. Laparoscopic or minimally-invasive fellowships were offered in $30.4 \%$ of centres, $64.7 \%$ of which included endourology training. In centres with a fellowship program, $23.5 \%, 35.3 \%$ and $41.2 \%$ of respondents stated fellows had a negative, neutral or positive affect on their training, respectively. Approximately $58.9 \%$ of respondents stated that no laparoscopic or minimally-invasive surgical research is performed at their institution.

\begin{tabular}{|c|c|c|c|c|}
\hline & 2007 & $\%$ & 2008 & $\%$ \\
\hline No. residents & 28 & 100 & 28 & 100 \\
\hline \multicolumn{5}{|l|}{ Sex } \\
\hline Male & 23 & 82.1 & 27 & 96.4 \\
\hline Female & 5 & 17.9 & 1 & 3.6 \\
\hline \multicolumn{5}{|l|}{ Province } \\
\hline Nova Scotia & 4 & 14.3 & 3 & 10.7 \\
\hline Ontario & 8 & 28.6 & 11 & 39.2 \\
\hline Quebec & 8 & 28.6 & 7 & 25 \\
\hline Manitoba & 0 & 0 & 2 & 7.1 \\
\hline Alberta & 1 & 3.6 & 1 & 3.6 \\
\hline British Columbia & 3 & 10.7 & 3 & 10.7 \\
\hline Did not state & 4 & 14.3 & 1 & 3.6 \\
\hline \multicolumn{5}{|l|}{ Age } \\
\hline $25-30$ & 10 & 35.7 & 10 & 35.7 \\
\hline $30-35$ & 18 & 64.3 & 17 & 60.7 \\
\hline$>35$ & 0 & 0 & 1 & 3.6 \\
\hline
\end{tabular}

\section{Laparoscopic renal surgery for malignancy}

In their final year, $33.9 \%$ of respondents had performed more than 20 radical nephrectomies, with $68 \%$ having performed more than 10 radical nephrectomies. The vast majority $(98.2 \%)$ of Canadian residents planned on performing laparoscopic radical nephrectomies in the next year and believed laparoscopic radical nephrectomy to be the gold standard $(96.4 \%)$. Approximately $82 \%$ of residents had participated in a laparoscopic partial nephrectomy in 2008, compared to $64.3 \%$ in 2007 .

\section{Laparoscopic donor nephrectomy}

Approximately $52.6 \%, 23.7 \%$ and $23.7 \%$ of residents reported that laparoscopic donor nephrectomy was performed solely by urologists, general surgeons or shared equally, respectively. In their final year, 51.8\% had not participated in laparoscopic donor nephrectomy. Of those respondents who had exposure, $7.1 \%$ had participated in a laparoscopic donor nephrectomy more than 20 times, $7.1 \%$ had participated in 10 to 20 donor nephrectomies, $7.1 \%$ had participated in 6 to 10, and 26.8\% had participated in less than 5. Despite the limited exposure to laparoscopic donor nephrectomies, $62.5 \%$ stated that laparoscopic donor nephrectomy is the current gold standard.

\section{Laparoscopic adrenal surgery}

At Canadian institutions, laparoscopic adrenalectomy was performed by $32.1 \%, 17.9 \%$, or $50 \%$ of general surgeons, urologists, or shared equally, respectively. In their final year, 
Preston et al.

\begin{tabular}{|c|c|c|}
\hline Subject & $2007, \%$ & $2008, \%$ \\
\hline \multicolumn{3}{|l|}{ Laparoscopic surgery } \\
\hline $\begin{array}{l}\text { Residents who have participated in more } \\
\text { than } 10 \text { laparoscopic radical } \\
\text { nephrectomies in the last year }\end{array}$ & 64 & 71 \\
\hline $\begin{array}{l}\text { Residents who believe laparoscopic radical } \\
\text { nephrectomy to be the gold standard }\end{array}$ & 93 & 100 \\
\hline $\begin{array}{l}\text { Residents who have participated in a } \\
\text { laparoscopic radical prostatectomy in } \\
\text { the last year }\end{array}$ & 64 & 68 \\
\hline $\begin{array}{l}\text { Residents who believe laparoscopic } \\
\text { radical prostatectomy looks promising }\end{array}$ & 61 & 46 \\
\hline \multicolumn{3}{|l|}{ Robotic surgery } \\
\hline $\begin{array}{l}\text { Residents training at institutions where } \\
\text { urological robotic procedures are performed }\end{array}$ & 4 & 36 \\
\hline $\begin{array}{l}\text { Residents who think robotic surgery will } \\
\text { increase in the future }\end{array}$ & 75 & 71 \\
\hline $\begin{array}{l}\text { Residents who plan on doing robotic } \\
\text { surgery after residency }\end{array}$ & 29 & 39 \\
\hline \multicolumn{3}{|l|}{ Education } \\
\hline $\begin{array}{l}\text { Residents who train at institutions with } \\
\text { fellowship-trained laparoscopic surgeons }\end{array}$ & 77 & 86 \\
\hline $\begin{array}{l}\text { Residents who rank their current experience } \\
\text { with laparoscopy as good or extensive }\end{array}$ & 71 & 64 \\
\hline $\begin{array}{l}\text { Residents who plan on doing fellowship } \\
\text { after residency }\end{array}$ & 73 & 79 \\
\hline $\begin{array}{l}\text { Proportion of residents pursuing a } \\
\text { fellowship in laparoscopy }\end{array}$ & 37 & 50 \\
\hline \multicolumn{3}{|l|}{ Percutaneous nephrolithotomy } \\
\hline $\begin{array}{l}\text { Residents training at institutions where } \\
\text { percutaneous access is obtained primarily } \\
\text { by urologists }\end{array}$ & 43 & 32 \\
\hline $\begin{array}{l}\text { Residents who plan on performing their } \\
\text { own percutaneous access in the future }\end{array}$ & 63 & 37 \\
\hline \multicolumn{3}{|l|}{ Percutaneous ablative surgery } \\
\hline $\begin{array}{l}\text { Residents training at institutions where } \\
\text { percutaneous needle ablative procedures } \\
\text { are performed }\end{array}$ & 61 & 82 \\
\hline $\begin{array}{l}\text { Proportion of these percutaneous } \\
\text { procedures performed by radiologists }\end{array}$ & 71 & 61 \\
\hline
\end{tabular}

$60.7 \%$ of respondents had participated in fewer than 5 adrenalectomies, with a further $28.6 \%$ with no experience in performing laparoscopic adrenalectomy. Despite the limited experience, most respondents $(78.6 \%)$ believed that laparoscopic adrenalectomy is the current gold standard.

\section{Laparoscopic pyeloplasty}

Approximately $78.6 \%$ of residents participated in a laparoscopic pyeloplasty in 2008, compared to $64.3 \%$ in 2007.

\section{Laparoscopic radical prostatectomy}

In 2007 and 2008, 66\% of residents participated in at least 1 laparoscopic radical prostatectomy, with $29 \%$ participating in more than 15 cases. Only 3.6\% of respondents believed that laparoscopic prostatectomy is the gold standard. However, $53.6 \%$ thought that the procedure looked promising and $67.9 \%$ planned on participating in 1 procedure during the coming year.

\section{Robotic-assisted laparoscopic surgery}

In 2008 , about $35.7 \%$ of residents had access to a surgical robot and $7 \%$ consider themselves trained in robotic-assisted procedures, compared to $3.6 \%$ and $3.6 \%$ in 2007 , respectively. Only $28.6 \%$ of 2007 residents thought they would be performing robotic surgery in their career compared to $39.3 \%$ in 2008 . Approximately $73.2 \%$ of respondents believed that robotic surgery would increase in the future. Eleven percent of residents believed robotic surgery is a fad that will fail, $41 \%$ believe it is not a fad and $48 \%$ were unsure.

\section{Endourologic surgery}

Flexible ureteroscopy and percutaneous nephrolithotomy were performed by $98.2 \%$ of residents in their final year. Approximately $39.3 \%$ of respondents reported performing $>50$ flexible ureteroscopic procedures in the past year and $33.9 \%$ reported participating in $>20$ percutaneous nephrolithotomies. Approximately $37.5 \%$ of residents trained at a centre where urologists have primary renal access for percutaneous procedures, with a further $30.4 \%$ being performed jointly by urologists and radiologists and $32.1 \%$ being performed only by radiologists. Half of the respondents planned on performing their own percutaneous renal access in the future.

\section{Ablative therapy for renal tumours}

Approximately 71.4\% (40/56) of Canadian residents reported that percutaneous needle ablation of kidney tumours is being performed at their institution; most of which (65\%) are performed by radiologists. Laparoscopic ablation procedures were performed at the institutions of only $30.4 \%$ of residents. While $51.8 \%$ of respondents believe it is too early to judge the effectiveness of ablative surgery, $37.5 \%$ believe that it looks promising. Most respondents $(67.9 \%)$ do not plan on performing an ablative procedure in the next year.

\section{Discussion}

The objective of this national survey was to determine the extent of laparoscopic, robotic and minimally-invasive surgery at training institutions in Canada, and to determine 
resident opinion and involvement for these procedures. All surveyed residents were scheduled to enter into further fellowship training or go directly into practice.

Laparoscopic surgery is increasingly prevalent in Canada. This reality is reflected in the large proportion of residents who operated with fellowship-trained laparoscopic surgeons and most who trained at a centre performing more than 50 laparoscopic procedures a year. The volume and quality of resident exposure to laparoscopic surgery should continue to increase as more fellowship-trained surgeons enter practice at academic centres.

Laparoscopic radical nephrectomy is widely accepted by urology residents across Canada to be the gold standard for clinically localized renal tumours when partial nephrectomy is not possible. Approximately $68 \%$ of residents performed over 10 radical nephrectomies in their final year, and most planned to perform them in the upcoming year. The high volume of radical nephrectomies conducted by residents has resulted in improved comfort and proficiency in laparoscopic surgery, likely similar to advancements in minimally-invasive general surgery secondary to experience performing laparoscopic cholecystectomy.

In 2008, approximately $82 \%$ of residents participated in a laparoscopic partial nephrectomy and $79 \%$ of residents participated in a laparoscopic pyeloplasty. While these percentages are increased from 2007, it is widely accepted that a certain threshold of exposure to more advanced procedures is required to obtain and maintain proficiency. Shay and colleagues found that urologists were more likely to perform laparoscopic procedures that they had been trained in during their residency $(69 \%)$ than if they had no experience during residency $(34 \%){ }^{2}$ It may be extrapolated that this would be especially true of more advanced laparoscopic procedures, such as pyeloplasty or partial nephrectomy, which are performed much less frequently. To achieve surgical proficiency, optimize outcomes and improve training for advanced minimally-invasive techniques, such procedures may have to be concentrated in high-volume centres.

Two-thirds of Canadian urology residents have participated in a laparoscopic prostatectomy in the past year and half of them believe that the procedure shows promise. Despite these improvements in experience and attitudes, laparoscopic prostatectomy remains a difficult laparoscopic procedure to teach. Few centres have adequate volume to achieve consistent resident exposure and training in laparoscopic prostatectomy. Further measures to improve residency proficiency in advanced laparoscopic procedures may include "block" surgery ${ }^{3}$ where mentorees progress gradually through key surgical steps or "blocks" that are assigned different levels of difficulty, mentor-initiated approaches, ${ }^{4}$ and task-specific bench model training. ${ }^{5}$

The widespread adoption of robotic-assisted radical prostatectomy in the United States and the emergence of robotic platforms in Canada are further changing the face of radical prostatectomy in Canadian residency training programs. Exposure and training in robotic-assisted laparoscopic procedures seem to be increasing; $35.7 \%$ of 2008 residents have access to a surgical robot and $7 \%$ consider themselves trained in robotic-assisted procedures, compared to $3.6 \%$ and $3.6 \%$ in 2007, respectively. This trend is a marked contrast from Duchene and colleagues who revealed that about $54 \%$ of American institutions perform robotic surgery. ${ }^{1}$ Despite the limited exposure in Canada, 34\% of residents intend on performing robotic procedures some time in their career and $73 \%$ believe robotic surgery will increase in the future. While it is important to adapt and incorporate novel technology in clinical practice, it is incumbent upon Canadian residency training program directors to continually evaluate the needs of urological residents. Residency programs must ensure adequate surgical training in standard operative cases, such as open radical retropubic prostatectomy, as most residents who enter practice after residency will have little or no access to robotics in the foreseeable future.

Clinical areas in need of further improvement include certain laparoscopic procedures, such as laparoscopic donor nephrectomy and adrenalectomy, renal ablative techniques and percutaneous access. Laparoscopic living donor nephrectomy is now the preferred technique for living donor renal transplantation. First reported by urologists in $1996,{ }^{6}$ this approach has been adopted by transplant centres worldwide. ${ }^{7}$ Similar experiences and attitudes were reported by Canadian residents compared with their American colleagues. Most respondents believed laparoscopic donor nephrectomy was the gold standard; however, over half of respondents had not participated in this procedure, likely due to general surgical renal transplantation programs. A urologist's unique familiarity with renal anatomy and physiology, in light of the advances and clinical volumes with laparoscopic nephrectomy, necessitate further expansion of urological transplantation programs.

It would also be beneficial to reinstate laparoscopic adrenalectomy in Canadian urology training programs. Adrenalectomy, traditionally a procedure in a urologist's armamentarium, was lost to general surgery during the expansion of laparoscopic general surgical procedures of the late 1980s and early 1990s, despite initial reports of laparoscopic adrenalectomy by urologists in the early 1990s. ${ }^{8,9}$ Twenty-eight percent of respondents had not participated in a laparoscopic adrenalectomy despite the overwhelming majority declaring it the current gold standard. Interestingly, despite the limited exposure to this procedure, $82.1 \%$ of residents plan to perform laparoscopic adrenalectomy in the upcoming year. This desire is likely the result of excellent exposure and training in laparoscopic nephrectomy techniques or opportunities during fellowship. 
Preston et al.

Lastly, both percutaneous renal access for calculus disease and percutaneous renal ablative techniques are technical areas that need improvement. A 2003 American survey of practice patterns in the treatment of large renal stones revealed that only $11 \%$ of urologists performing percutaneous nephrolithotomy routinely obtained the percutaneous access themselves. ${ }^{10}$ Only $37.5 \%$ of Canadian residents train at centres where urologists obtain primary renal access for percutaneous procedures despite recent evidence to suggest improved stone-free rates and lower complication rates with urologist-obtained renal access. ${ }^{11}$ Similar to renal access rates, most of the percutaneous thermal ablation procedures for kidney tumours are being performed primarily by radiologists. Despite ablative procedures becoming increasingly available as an alternative therapy for the management of small renal masses, most residents do not plan to perform ablations in the future. These technical skill sets warrant closer evaluation and likely inclusion in urological programs as the primary underlying disease processes, namely renal calculus disease and renal masses, are managed primarily by urologists.

Training in minimally-invasive surgery in Canada has steadily improved over the past few years. Most residents (68\%) state that their laparoscopic training is good or extensive. Despite these favourable results, of the $76 \%$ of residents pursuing a fellowship, 54\% will be furthering their training in laparoscopy or endourology. These statistics are similar to those acquired in a study by Fazio and colleagues, which found that $78 \%$ of residents went on to a fellowship, $36 \%$ of which included laparoscopy. ${ }^{12}$ Reasons for this trend are not fully elucidated but it may suggest that a significant proportion of residents feel that they need more training to either perform certain advanced procedures or to perform laparoscopy independently in practice. In our study, $13 \%$ of respondents found their training to be below average or poor. It is unclear what aspects of the laparoscopic experience in residency were deemed to be inadequate. One hypothesis is that the steep learning curve associated with laparoscopic and endourologic procedures may limit residents from becoming proficient in these areas. Simulated laparoscopic training is developing across the country as $70 \%, 75 \%$ and $29 \%$ of residents had access to wet surgical laboratories, pelvic trainers and virtual reality simulators, respectively. These training methods may have the potential to decrease the laparoscopic learning curve as they are further validated in the future.

This study is limited for several reasons. Selection bias may be present as some residents may not have attended QUEST. Due to the retrospective format of the survey, recall bias may be present. Centres that train more residents were more heavily weighted compared to smaller training programs that were relatively under-represented. Lastly, the study represents resident perceptions only and may not completely reflect the true status of the various resident training programs.

\section{Conclusion}

In Canadian residency training programs, fellowship-trained urologists commonly perform laparoscopic surgery. Laparoscopic nephrectomy is commonly performed and is considered the standard of care by Canadian urology residents. Minimally-invasive surgical fellowships remain popular. Robotic-assisted surgery is becoming more common but will require continued evaluation by educators who will ultimately define its role in the urological residency training curriculum. In addition, percutaneous renal access techniques and percutaneous renal mass ablation are not commonly performed by urologists and will likely require fellowship-trained clinical leaders to disseminate these skills to practising urologists and future trainees. With everchanging technological advances, urologists must strive to learn new procedures or risk losing their position as the primary treatment provider for certain urologic conditions.

From the *Division of Urology, University of Ottawa, Ottawa, ON; †Department of Urology, Queen's University, Kingston, ON

Competing interests: None declared.

This paper has been peer-reviewed.

\section{References}

1. Duchene DA, Moinzadeh A, Gill IS, et al. Survey of residency training in laparoscopic and robotic surgery. J Urol 2006;176:2158-66.

2. Shay BF, Thomas R, Monga M. Urology practice patterns after residency training in laparoscopy. $J$ Endourol 2002;16:251-6.

3. Matsumoto ED, Webster TM, Blew B, et al. Teaching laparoscopic radical prostatectomy in academic and private hospitals: the mentored approach. Can Urol Assoc J 2007;1:143.

4. Fabrizio MD, Tuerk I, Schellhammer PF. Laparoscopic radical prostatectomy: decreasing the learning curve using a mentor initiated approach. J Urol 2003;169:2063-5.

5. Sabbagh R, Chatteriee $S$, Chawla A, et al. Task-specific bench model training versus basic laparoscopic training for laparoscopic radical prostatectomy: a randomized controlled study. Can Urol Assoc J 2009;3:22-30.

6. Schulam PG, Kavoussi $L R$, Cheriff $A D$, et al. Laparoscopic live donor nephrectomy: the initial 3 cases. J Urol 1996;155:1857-9.

7. Wright AD, Will TA, Holt DR, et al. Laparoscopic living donor nephrectomy: a look at current trends and practice patterns at major transplant centres across the United States. J Urol 2008; 179:1488-92.

8. Peschel R, Janetschek G, Reissigl A, et al. Left-sided laparoscopic adrenalectomy. Scand I Urol Nephrol 1993:27:527-9.

9. Higashihara E, Tanaka Y, Horie S, et al. Laparoscopic adrenalectomy: the initial 3 cases. J Urol 1993;149:973-6.

10. Bird VG, Fallon B, Winfield HN. Practice patterns in the treatment of large renal stones. J Endourol 2003;17:355-63

11. Watterson JD, Soon S, Jana K. Access related complications during percutaneous nephrolithotomy: urology versus radiology at a single academic institution. J Urol 2006:176:142-5.

12. Fazio $L M$, Dagnone AJ, Blew BD, et al. The laparoscopic experience of recently trained Canadian urologists. Can I Urol 2006;13:3047-52.

Correspondence: Dr. James Watterson, Division of Urology, Department of Surgery, The Ottawa Hospital - General Campus, 501 Smyth Rd., Ottawa, ON K1H 8L6; fax: 613-737-8982; jwatterson@ottawahospital.on.ca 